\title{
EVALUATION OF TILMICOSIN IN TREATMENT OF MYCOPLASMA GALLISEPTICUM INFECTED CHICKENS
}

\author{
L.K. ABD EL-SAMIE \\ Colleague at Vet. Hospital, Faculty of Vet. Med., Zagazig Univ., Egypt \\ Email: lamahsamie@gmail.com
}

\section{ABSTRACT}

Received at: 9/6/2014

Accepted: 13/8/2014
Tilmicosin is a macrolide antibiotic used in this study for management of experimentally infected chicken with Mycoplasma gallisepticum $(\mathrm{Mg})$. Its efficacy was assessed by ELISA, re-isolation, lesion score and performance parameters. One hundred and ten day old chicks, tested negative M. gallisepticum, were deployed and equally divided into four groups in separate rooms. On the third week of age, group B was inoculated with $0.2 \mathrm{ml}$ of $M$. gallisepticum broth $\left(10^{8} \mathrm{CFU}\right)$ into air sac. Group A was likewise infected but treated with tilmicosin phosphate in drinking water at fourth week of age. Group C treated in the same way but not infected while group D was left as control not infected/treated. On weekly basis swabs and serum samples were collected from each group for bacteriology and serology meanwhile morbidity, mortalities and weight gain were recorded. At the end of the experiment results showed that there was no significant differences in mean body gain of groups A, C and D $1606.61 \pm 5.79^{\mathrm{b}}, 1658.04 \pm 17.01^{\mathrm{a}}, 1624.60 \pm 17.36^{\mathrm{ab}}$, respectively while there was significant reduction of ELISA antibody titer of group A which recorded $441.22 \pm 7.57^{\mathrm{b}}$ probable reactors confirmed negative by bacteriological isolation comparing with group B positive $M g$ at titer $1011.30 \pm 40.92^{\mathrm{a}}$. It is proved that medication with tilmicosin phosphate in drinking water for 3 successive days was effective in curing of induced M. gallisepticum infection, moreover it was successful to overcome economic problem due to weight loss consequently marketability.

Key words: Tilmicosin - Mycoplasma gallisepticum - Body weight - ELISA

\section{INTRODUCTION}

Respiratory infection is the most serious disease affecting poultry and causes heavy economic losses in the poultry industry worldwide (Murthy et al., 2008). A flock of 12000 commercial broilers of 3 weeks age were observed to exhibit the clinical signs like dullness, anorexia, sneezing, coughing with facial edema, which was tentatively diagnosed for respiratory disease (Mujeeb et al., 2009). Mycoplasma gallisepticum is the major mycoplasma pathogen in poultry which causes chronic respiratory disease in chickens and infectious sinusitis in turkeys resulting in stunted growth with high mortality rates among young birds and high condemnations at processing plants (Levisohn and Kleven, 2000).

Macrolide antibiotics have been used in the treatment of bacterial infections for many years; they inhibit protein biosynthesis by binding to ribosomal RNA (rRNA) of the bacterial ribosome to exhibit antibiotic activities (Vester and Douthwaite, 2001). Recent work suggests that incorporation of $300-500 \mathrm{mg} / \mathrm{kg}$ tilmicosin in feed was effective in the treatment of
Mycoplasma gallisepticum in broiler chickens (Shryock et al., 1994). In practice, however, most poultry production units would prefer to treat disease outbreaks by incorporating the antibiotic agent into the drinking water. Therefore, a series of studies was required to investigate the efficacy of administering tilmicosin in drinking water against $M$. gallisepticum (Charleston et al., 1998).

This work focused on the efficacy of tilmicosin against M. gallisepticum infection in chickens regarding clinical symptoms, mortalities, body weight, lesion score, bacterial recovery.

\section{MATERIALS and METHODS}

Experimental birds: One hundred ten apparently healthy day old chicks (Arbor Acer) sourced from Commercial hatchery; ten chicks randomly selected, humanly euthanized and tested negative M. gallisepticum by using ELISA and bacteriological examination. Chicks were fed on commercial unmedicated balanced ration ( $21 \%$ protein) and divided equally into 4 groups ( 25 each) in separated room 
under hygienic conditions, feed and water provided ad libtum (Table1).

Macrolide antibiotic: Tilmicosin phosphate (Pneumotac solution each $\mathrm{ml}$ contain $300 \mathrm{mg}$ ) administered in drinking water $(0.5 \mathrm{ml} /$ liter $)$ daily for 3 successive days.

Bacterial strain: Mycoplasma gallisepticum (strain S6), Animal Health Research Institute, El-Dokki, Giza, used for experimental infection via air sacs inoculation with $0.2 \mathrm{ml}\left(10^{8}\right.$ C.F.U.) according to (Ellakany et al., 1997).

Clinical findings and lesion score: Post infection morbidity and mortalities were recorded and estimated in percentage. At necropsy lesion determined the severity of air sacs infection and scored as follows: (1) No lesions, (2) Cloudiness of air sacs, (3) Air sac membranes thickened, (4) cheesy appearance of sacs, according to (Kempef et al., 1997).

Performance parameters and Blood sampling: At 21 day old to 49 days old birds of each group weighed on weekly basis for calculation of body weight gain and blood samples were taken by wing vein puncture for serological examination.

Bacteriological examination: Swabs were collected weekly from live (oro-pharyngeal) and dead birds (air sac) from each group post infection/treatment for isolation of $M$. gallisepticum according to (Kleven 2008). Briefly dry swabs were dipped several times in Frey's media and then discarded. Inoculated media were incubated at $37^{\circ} \mathrm{C}$ for at least 10 days or until a color change was evident.

Serological test: Commercial ELISA kits for Mycoplasma gallisepticum antibody evaluation (ProFLOK - Synbiotics. M-0062-0309) and was carried out according to manufacture instruction. Optical density was recorded and antibody titer estimated as follows:

$\mathrm{SP}$ value $=\quad$ OD value of sample - OD value of negative control

OD value of positive control - OD value of negative control

$\log _{10}$ titer $=1.464 \times \log _{10}(\mathrm{SP})+3.197$

Result interpretation: titer levels $0-148$ (Negative), 194-743 (Probable), 744 and higher (Positive).
Statistical analysis: Data were collected, organized and analyzed using one-way analysis of variance (ANOVA) through the general linear models (GLM) procedure of the Statistical Package for Social Sciences version 17.0 (SPSS for Windows 17.0, Inc., Chicago, IL, USA). Duncan multiple range test were used to separate means at $\mathrm{p}<0.05$.

\section{RESULTS}

Infected group B with M. gallisepticum, showed morbidity in the form of loss of appetite, depression, sneezing, gasping, mild conjunctivitis and frothy exudation in the eyes with mortality of 15 birds out of $25(60 \%)$ along 12 days post infection while group A showed milder symptoms with 2 mortality (8\%) along 7days before treatment with tilmicosin. On necropsy of the dead birds air sac lesion of group B was scored 4 (cheesy air sac) while group A was 2 (cloudy air sac). No clinical signs, mortalities or lesion score were recorded in groups C and D (Table 2). Bacteriological isolation from oropharyngeal swabs of live birds and air sac from dead ones showed the highest recovery of $M$. gallisepticum in group B where all birds were positive up to the end of experiment while group A, tilmicosin reduced the number of positive birds along 2 weeks post medication. Moreover M. gallisepticum recovery was negative at 49 days old. Chickens of both groups D and $\mathrm{C}$ were negative $M$. gallisepticum culture (Table 2). At 42 and 49 days old, treated not infected group $\mathrm{C}$ recorded the highest mean body weight 1549.24gm and $2407.36 \mathrm{gm}$ respectively, but statistically there was no significant difference when compared with the control group D. Infected not treated group B showed the lowest mean body weight $1427.60 \mathrm{gm}$ and 2159.00gm respectively, with significant difference on comparison with the other groups. Group A, infected treated chickens with tilmicosin showed a significant increase in mean body weight than infected group B. Moreover at the end of the experiment, chickens of group A recorded mean body weight 2367.04gm without significant difference with group D and C (Table 3). ELISA screening reflected that group A not only had significantly lower positive geometric mean titer (932.22) of $M$. gallisepticum, one week post treatment with tilmicosin, but also had probable titer (603.30) and negative titer (441.22) at 42 and 49 days old respectively, than group $B$ which had positive titer $(1065.90,1395.90$ and 1011.30$)$ at 35 , 42 and 49 days old respectively. 
Table 1: Experimental design.

\begin{tabular}{|c|c|c|c|c|c|c|c|}
\hline Grp & No. & Tilmicosin treatment & $\begin{array}{l}\text { Infection with } M . \\
\text { gallisepticum }\end{array}$ & \multicolumn{4}{|c|}{ Evaluation } \\
\hline $\mathbf{A}$ & 25 & 28 days old & \multirow{2}{*}{$\begin{array}{l}21 \text { days old with } 0.2 \mathrm{ml} \\
\text { via air sacs }\left(2 \times 10^{8} \text { C.F.U) }\right.\end{array}$} & \multirow{4}{*}{ 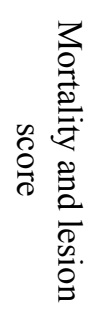 } & \multirow{4}{*}{\multicolumn{2}{|c|}{ 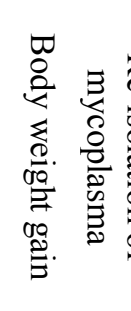 }} & \\
\hline B & 25 & Negative & & & & & 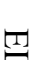 \\
\hline $\mathbf{C}$ & 25 & 28 days old & Negative & & & & $>$ \\
\hline D & 25 & \multicolumn{2}{|c|}{ Negative } & & & & \\
\hline
\end{tabular}

Table 2: Effect of Tilmicosin on pathogenicity of M. gallisepticum.

\begin{tabular}{|c|c|c|c|c|c|c|c|c|}
\hline \multirow{2}{*}{ Groups } & \multirow{2}{*}{$\begin{array}{l}\text { No. of } \\
\text { birds }\end{array}$} & \multicolumn{2}{|c|}{ Mortality } & \multirow{2}{*}{$\begin{array}{l}\text { Air sac } \\
\text { lesion } \\
\text { score }\end{array}$} & \multicolumn{4}{|c|}{ Re-isolation of $M g$ post infection } \\
\hline & & No & $\%$ & & 28 d.o. & 35 d.o. & 42 d.o. & 49 d.o. \\
\hline A & 25 & 2 & 8 & 2 & 15 & 5 & 2 & 0 \\
\hline $\mathrm{B}$ & 25 & 15 & 60 & 4 & 22 & 19 & 10 & 10 \\
\hline $\mathrm{C}$ & 25 & 0 & 0 & 1 & 0 & 0 & 0 & 0 \\
\hline $\mathrm{D}$ & 25 & 0 & 0 & 1 & 0 & 0 & 0 & 0 \\
\hline
\end{tabular}

d.o. age of birds in days

Table 3: Effect of Tilmicosin treatment on performance of chickens.

\section{Groups}

A

Mean B.wt (gm)*

\begin{tabular}{ccccc}
\hline 21 days old & $753.78 \pm 2.03^{\mathrm{a}}$ & $762.10 \pm 5.94^{\mathrm{a}}$ & $749.32 \pm 4.38^{\mathrm{a}}$ & $754.48 \pm 1.81^{\mathrm{a}}$ \\
\hline 28 days old & $1107.65 \pm 2.89^{\mathrm{b}}$ & $1109.80 \pm 4.93^{\mathrm{b}}$ & $1151.68 \pm 6.41^{\mathrm{a}}$ & $1157.92 \pm 8.58^{\mathrm{a}}$ \\
\hline 42 days old & $1473.22 \pm 4.80^{\mathrm{b}}$ & $1427.60 \pm 7.93^{\mathrm{c}}$ & $1549.24 \pm 8.91^{\mathrm{a}}$ & $1531.60 \pm 8.30^{\mathrm{a}}$ \\
\hline 49 days old & $2367.04 \pm 5.79^{\mathrm{a}}$ & $2159.00 \pm 18.76^{\mathrm{b}}$ & $2407.36 \pm 16.21^{\mathrm{a}}$ & $2379.08 \pm 16.89^{\mathrm{a}}$ \\
\hline B.gain $* *$ & $1606.61 \pm 5.79^{\mathrm{b}}$ & $1396.90 \pm 18.75^{\mathrm{c}}$ & $1658.04 \pm 17.01^{\mathrm{a}}$ & $1624.60 \pm 17.36^{\mathrm{ab}}$ \\
\hline
\end{tabular}

* Means within the same raw carrying different superscript are significantly different at $P$ value $<0.05$

** Cumulative Mean body gain of 4weeks (21 - 49 days old)

Table 4: Result of ELISA reflecting antibody titer of $M$. gallisepticum.

\begin{tabular}{ccccc}
\hline \multirow{2}{*}{ Grp } & \multicolumn{4}{c}{ Mean antibody titer* } \\
\cline { 2 - 5 } & 28 days old & 35 days old & 42 days old & 49 days old \\
\hline A & $845.74 \pm 12.66^{\mathrm{a}}$ & $932.22 \pm 9.63^{\mathrm{b}}$ & $603.30 \pm 8.44^{\mathrm{b}}$ & $441.22 \pm 7.57^{\mathrm{b}}$ \\
\hline B & $868.90 \pm 24.01^{\mathrm{a}}$ & $1065.90 \pm 22.60^{\mathrm{a}}$ & $1395.90 \pm 51.56^{\mathrm{a}}$ & $1011.30 \pm 40.92^{\mathrm{a}}$ \\
\hline D & $0.00 \pm 0.00^{\mathrm{b}}$ & $0.00 \pm 0.00^{\mathrm{c}}$ & $0.00 \pm 0.00^{\mathrm{c}}$ & $0.00 \pm 0.00^{\mathrm{c}}$ \\
\hline C & $0.00 \pm 0.00^{\mathrm{b}}$ & $0.00 \pm 0.00^{\mathrm{c}}$ & $0.00 \pm 0.00^{\mathrm{c}}$ & $0.00 \pm 0.00^{\mathrm{c}}$ \\
\hline
\end{tabular}

* Means within the same column carrying different superscript are significantly different at $P$ value $<0.05$ 


\section{DISCUSSION}

Although Jordan and Horrocks (1996) used the antibiotic dissimilarly (concentration and duration wise), their results agreed with ours where they reported that untreated infected group of chickens with M. gallisepticum showed 16 out of 30 birds with clinical signs while mortalities was significantly less in infected and treated group with tilmicosin with greater body weight gains. M. gallisepticum was recovered from 4 life and 4 dead birds in groups that treated with tilmicosin at concentration of 0.12 $\mathrm{gm} /$ liter drinking water, however organism was not recovered from birds treated with higher doses. Serological results of treated groups at different concentrations of $0.125,0.25$ or $0.5 \mathrm{~g} /$ liter of tilmicosin were negative. Kempf et al. (1997) inoculated chicks differently at 10 days of age with M. gallisepticum during administration of tilmicosin medicated water (8-11 days old) at levels of 5-300 $\mathrm{mg} / \mathrm{liter}$ but recorded matched results as treated groups showed significantly decreased growth losses, respiratory signs $(\mathrm{P}<0.05)$ with reduction in air sac and peritonitis lesions. Moreover increasing the dose resulted in a further decrease in the number of $M$. gallisepticum shedding to the extent that with the two highest doses of tilmicosin, no bird was serologically positive on day 21 , compared to $46 / 58$ positively infected untreated birds (day 21). In spite of conducting two experiments using medicated water with tilmicosin at different levels and duration, Charleston et al. (1998) suggested similarly that the drug was effective in reducing the incidence and severity of airsaculitis lesions caused by $M$. gallisepticum without effect on the morbidity at 50,75 and $100 \mathrm{mg} /$ liter. The minimum effective concentration of tilmicosin in drinking water appears to be at or less than $50 \mathrm{mg} /$ liter when administered for either 3 or 5 days. Even Jordan et al. (1999) used tilmicosin in treatment of turkey poults infected with M. gallisepticum at 2 days old unlike our study but agreed in the outcome as they mentioned that mortality, clinical signs, and gross lesions were significantly less $(\mathrm{P}<0.001)$ in the uninfected and infected medicated groups than in the infected unmedicated one. Also, the mean body weight gain of poults surviving to the end of the experiment was greater $(\mathrm{P}<0.005)$ in the uninfected and infected medicated groups. $M$. gallisepticum was not recovered from the un-infected birds while it was recovered significantly fewer $(\mathrm{P}<0.05)$ in the medicated groups compared with infected ones. Serologic results were negative for the uninfected group, and there were fewer positive reactors for the infected medicated than the infected un-medicated group.

This study proved that ELISA detected seroconversion one week post challenge while Gharaibeh and Hailat (2011) mentioned that all tested chickens challenged with $M$. gallisepticum sero-converted positive two weeks post infection, also Asgharzade et al. (2013) detected positive reactors of $M$. gallisepticum by commercial ELISA kit from 6 to 7 weeks of age after challenge of chickens at third week of age with $M$. gallisepticum $\left(1 \times 10^{6} \mathrm{CFU} / \mathrm{bird}\right)$ via eye drop. These differences may be attributed to the age susceptibility, route and mode of infection, specificity of serological test, concentration and duration of medication as Leigh et al. (2012) emphasized that the intratracheal route of M. gallisepticum infection caused increased air sac and tracheal lesion scores and tracheal mucosal thickness at one week post infection, whereas the eye drop route produced no noticeable pathology. However, tracheal mucosal thicknesses of intratracheally challenged pullets were not statistically different from those of the eye drop challenged or control pullets at two and three weeks post infection.

It is concluded that tilmicosin phosphate in drinking water for 3 successive days at $150 \mathrm{mg} /$ liter was efficient enough to control the pathogenicity of Mycoplasma gallisepticum consequently reduction of economic losses caused by the infection and should be proved as a useful addition of the disease control in chickens.

\section{REFERENCES}

Asgharzade, S.; Zaeri, S.; Hasanzade, M.; Ahmadi, M. and Talebi, A.R. (2013): Detection of Mycoplasma gallisepticum in experimentally infected broiler chickens using Culture, SPA, ELISA and PCR methods. Comp Clin Pathol. 22: 1051-1055.

Charleston, B.; Gate, J.J.; Aitken, I.A. and ReeveJohnson, L. (1998): Assessment of the efficacy of tilmicosin as a treatment for Mycoplasma gallisepticum infections in chickens. Avian Pathology 27, 190-195.

Ellakany, H.; Katalin Fabian and Stipkovits, L. (1997): Immunoblot examination of humoral response of chickens infected with Mycoplasma gallisepticum at various age. Comp. Immun. Microbiol. Infect. Dis. Vol. 20, No. 4, pp. 319-333.

Gharaibeh, S. and Hailat, A. (2011): Mycoplasma gallisepticum experimental infection and tissue distribution in chickens, sparrows and pigeons. Avian Pathol. 40(4), 349-354.

Jordan, F.T. and Horrocks, B.K. (1996): The minimum inhibitory concentration of Tilmicosin and Tylosin for Mycoplasma gallisepticum and Mycoplasma saynoviae and a comparison of their efficacy in the control of Mycoplasma infection in broiler chickens. Avian Dis. 40(2), 326-334. 
Jordan, F.T.; Reeve-Johnson, L.; Gesbert, F. and Guitlet, M. (1999): The comparison on aqueous preparation of Tilmicosin with Tylosin in treatment of Mycoplasma gallisepticum infection of turkey poults. Avian Dis. 43(3), 521-525.

Kempf, I.; Forrester, C.A.; Hodge, A. and ReeveJohnson, L.G. (1997): Efficacy of Tilmicosin in the control of experimental Mycoplasma gallisepticum infection in chickens. Avian Dis. 41(4), 802-807.

Kleven, S.H. (2008): Mycoplasmosis. In: DufourZavala L, Swayne DE, Glisson JR, Pearson JE, Reed WM, Jackwood MW, Woolcock PR (eds) Laboratory manual for the isolation, identification and characterization of avian pathogens. American Association of Avian Pathologists, Athens, pp 59-64.

Leigh, S.A., Brnaton, S.L.; Evans, J.D. and Collier, S.D. (2012): Effect of infection route and concurrent infectious bronchitis virus vaccination on Mycoplasma gallisepticum disease pathology in an experimental model. Avian Pathol. 41(5): 497-503.
Levisohn, S. and Kleven, S.H. (2000): Avian mycoplasmosis (Mycoplasma gallisepticum). Rev. Sci. Tech. 19: 425-442.

Mujeeb, A.; Ravikanth, K.; Rekhe, D.S. and Maini, S. (2009): Effectiveness of conventional and alternative therapy in treatment of respiratory infections in poultry. Veterinary World, 2(8): 313-316.

Murthy, T.R.; Dorairajan, N.; Balasubramaniam, G.A.; Dinakaran, A.M. and Saravanabava, K. (2008): Pathogenic bacteria related to respiratory diseases in poultry with reference to Ornithobacterium rhinotracheale isolated in India. Vet. Arhiv. 78 (2): 131-140.

Shryock, T.R.; Klink, P.R.; Readnour, R.S. and Tonkinson, L.V. (1994): Effect of bentonite incorporated in a feed ration with tilmicosin in the prevention of induced Mycoplasma gallisepticum airsacculitis in broiler chickens. Avian Diseases, 38, 501-505.

Vester, B. and Douthwaite, S. (2001): Macrolide resistance conferred by base substitutions in 23S rRNA. Antimicrob Agents Chemother, 45(1): 1-12.

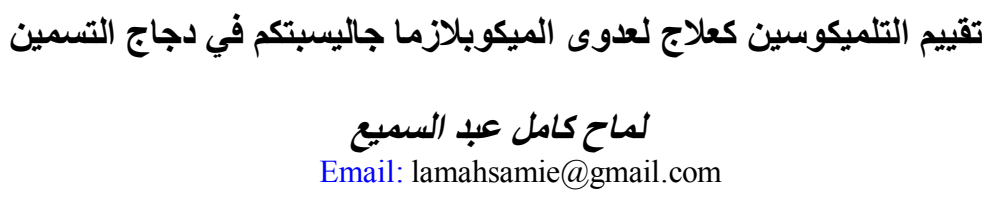

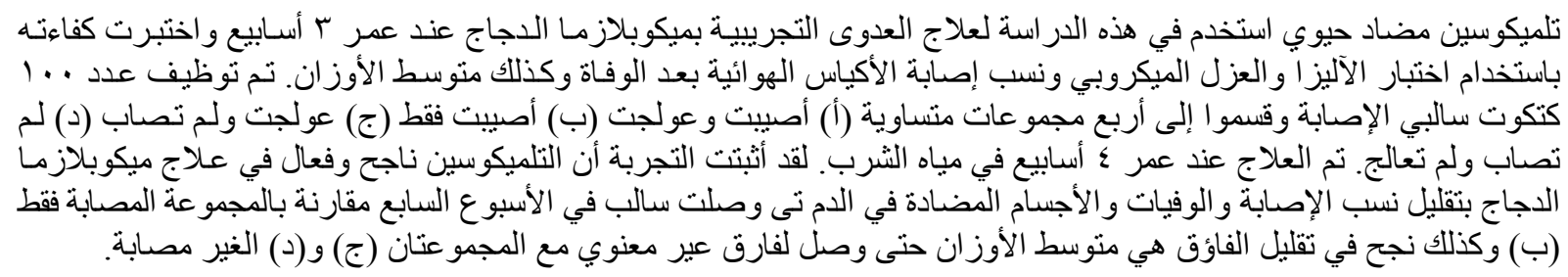

